\title{
Verbal and visuospatial short-term memory in children: Evidence for common and distinct mechanisms
}

\author{
SUSAN J. PICKERING, SUSAN E. GATHERCOLE, and SARAH M. PEAKER \\ University of Bristol, Bristol, England
}

\begin{abstract}
This study was designed to identify whether verbal and visuospatial short-term memory performance in children is served by common or distinct mechanisms. Five- and 8-year-old children were tested on their verbal recall of spoken letter names and digits, and on their recall of tapped sequences of blocks. The performance of the children on the verbal and visuospatial serial recall tasks was largely unrelated, extending evidence for dissociable memory systems found in adults. Detailed characteristics of recall, such as serial position functions, migration patterns, and distribution of error types, were similar in the tasks requiring recall of letters and of blocks, although order errors predominated in the block but not the letter recall task for the older children. These results appear to reflect the application of common processes specialized for the extraction of serial order information from the phonological and visuospatial components of short-term memory.
\end{abstract}

The study of short-term memory has long been characterized by its treatment of memory for verbal material such as lists of words, letters, and digits as separate from memory for visuospatial material such as abstract drawings, spatial locations of blocks, and images. Findings from many sources, including studies of special populations such as neuropsychological patients and individuals with learning disabilities, have converged upon the view that the cognitive capacities to maintain verbal and nonverbal material for short periods of time are independent of each other (e.g., Farah, Hammond, Levine, \& Calvanio, 1988; Hanley, Young, \& Pearson, 1991; Vallar \& Baddeley, 1984; Wang \& Bellugi, 1994). Recent evidence that short-term memory for verbal and visuospatial material is associated with activity in separate brain systems (e.g., Smith, Jonides, \& Koeppe, 1996) lends further weight to the view that immediate memory performance in the two domains is served by distinct short-term memory systems (see, e.g., Baddeley, 1986; Logie, 1995).

Some recent detailed analyses of performance in verbal and visuospatial memory tasks have, however, identified commonalities in the detailed characteristics of immediate memory for material presented in the two domains when task demands are equated. One distinction that has commonly been drawn between the characteristics of immediate memory for verbal and visuospatial material con-

This research was supported by the Medical Research Council of Great Britain. The authors wish to thank the children and staff of Christchurch and Elm Lea primary schools, in Bristol, for the time and cooperation that they generously contributed to this study. Correspondence should be addressed to S. J. Pickering, Department of Psychology, University of Bristol, 8 Woodland Road, Bristol BS8 ITN, England (e-mail: s.pickering@ bris.ac.uk). cerns the serial position function. For aurally presented verbal stimuli, a bow-shaped serial position curve is typical, reflecting superior serial recall of items at the beginning and end than at the middle of memory lists; these two features are known as primacy and recency effects, respectively. The recency component appears to be associated with memory for order rather than item information (Healy, 1974, 1982). Recall of visually presented nonverbal stimuli is more typically characterized by an absent or weak recency effect (Phillips \& Christie, 1977). It now appears that the disparity in recency profiles across the verbal and visuospatial domains may have more to do with lack of parity between tasks than with distinct memory mechanisms. Two recent studies of visuospatial memory employed paradigms in which subjects were required to recall the order of arbitrary elements located in twodimensional space (Jones, Farrand, Stuart, \& Morris, 1995; Smyth \& Scholey, 1996b). In both cases, recency effects of a magnitude characteristic of verbal short-term memory performance were found. On the basis of this and other evidence, Jones, Beaman, and Macken (1996) have developed a model of serial recall in which spatial and verbal materials share a common level of representation. The position advocated by Smyth and Scholey (1996b) is rather different; they have suggested that ordinal information may be handled in a corresponding manner across domains, but have maintained the view that the representational subsystems for verbal and visuospatial memory are distinct.

Further evidence for the contribution of common mechanisms to serial recall of both verbal and visuospatial material is provided by comparisons of serial order errors across the two domains. In both serial recall of lists of verbal stimuli such as letters (Bjork \& Healy, 1974; 
Conrad, 1965; Healy, 1974; Henson, Norris, Page, \& Baddeley, 1996) and of sequences of blocks (Smyth \& Scholey, 1996b), the most common category of order error is that of adjacent transpositions, in which pairs of items located successively in the input sequence exchange positions at output. The verbal and visuospatial serial order tasks also yield corresponding migration gradients: In both cases, incorrectly ordered elements at output tend to cluster around the target positions, with the majority of items moving to adjacent list positions (Henson et al., 1996; Smyth \& Scholey, 1996b).

Features of recall such as recency effects, the predominance of transposition errors, and the steep migration gradient in serial recall errors have each been simulated by a range of computational models advanced in recent years as accounts of verbal serial recall. The models vary considerably in nature, incorporating key features such as multilayer connectionist systems with context-learning mechanisms (Burgess \& Hitch, 1992, 1996), associative chaining processes (Lewandowsky \& Murdock, 1989), position-sensitive activation levels (Henson et al., 1996), and oscillator-based timing contexts (Brown, Preece, \& Hulme, 1997). The apparent correspondence between the serial order errors made in verbal and visuospatial tasks raises the possibility that the mechanisms and processes specialized for handling the maintenance and output of serial order need not be restricted to verbal memory and could be applied to memory representations in any domain, in line with suggestions made by Smyth and Scholey (1996b).

The present study investigated whether verbal and visuospatial short-term memory capacities in childhood show patterns of association and dissociation that are similar to the ones observed across different studies in adults. Developmental changes in verbal short-term memory have been extensively tested in recent years, and the ways in which children's initially poor verbal memory capacities come to approximate adult short-term memory function are now fairly well understood (for reviews, see Cowan \& Kail, 1996, and Gathercole \& Hitch, 1993). The average 4-year-old child has a verbal memory span for spoken memory lists of between two and three items, about a third of adult capacity. Span increases in a linear fashion during the school years (Hulme, Thomson, Muir, \& Lawrence, 1984; Nicolson, 1981). Up to about 7 years of age, children do not appear to spontaneously use a strategy of subvocal rehearsal to maintain a memory sequence; before this age, they fail to show lip movements during presentation of the memory list (Flavell, Beach, \& Chinsky, 1966), and their memory spans are independent of the rate at which they speak and would therefore rehearse (Gathercole, Adams, \& Hitch, 1994; Henry, 1994). Beyond about 7 years, these indicators of rehearsal are present (Flavell et al., 1966; Gathercole et al., 1994).

Rather less is known about the detail of children's immediate memory for visuospatial material (for reviews, see Gathercole \& Baddeley, 1993, and Logie, 1995). Memory for visual patterns increases with age (Wilson, Scott, \& Power, 1987), as does performance on the most popular visuospatial analogue of memory span, Corsi blocks (De Renzi \& Nichelli, 1975; Isaacs \& VarghaKhadem, 1989). In this task, the subject views a configuration of blocks laid out on a two-dimensional board. The blocks are tapped in a random sequence, and the subject's task is to reproduce the sequence. This task places a strong requirement to recall the order of arbitrary elements, in much the same way as does the digit span task that is present in many standardized ability tests (e.g., Elliott, 1983; Wechsler, 1974).

There is some limited evidence that children's skills on measures of verbal and nonverbal memory tasks are unrelated to each other. Michas and Henry (1994) found no significant correlations between the performance of 5 -year-old children on a Corsi-type spatial memory test and their performance on two measures of verbal shortterm memory, nonword repetition and memory span. Further evidence for a dissociation between verbal memory span and Corsi span was provided by Isaacs and Vargha-Khadem (1989). They showed that children are better at recalling digit sequences in a forward than a backward sequence, whereas equivalent memory spans were found for forward and backward recall of Corsi block sequences. It should, however, be noted that recent findings of Farrand and Jones (1996) indicate that comparable levels of forward and backward recall can also be obtained in verbal serial recall, if all of the items in the memory list are made available at recall, as in the case of the Corsi spatial memory task. This study demonstrates very clearly the interpretational problems raised by the lack of complete correspondence in the procedures used in conventional tests of verbal serial recall, on the one hand, and visuospatial serial recall, on the other.

Independence of children's verbal and visuospatial memory skills was also indicated by findings from a study by Liberman, Mann, Shankweiler, and Werfelman (1982) of the memory abilities of 8-year-old children of either good or poor reading ability. Although the two reading groups were distinguished in their abilities to recognize recently presented syllables (with the good readers outperforming the poorer children), they performed equivalently when the stimuli to be recognized were either faces or nonsense designs.

There has as yet been little direct comparison of the detailed characteristics of children's serial recall of verbal and visuospatial material. In the present study, we were particularly interested in three features of serial recall that have been extensively studied in adults-serial position functions, migration gradients, and serial order errors. Five- and 8-year-old children were tested on a digit span procedure and in two serial recall tasks: a verbal task involving the serial recall of letter names and a visuospatial task involving recall of the location of a series of tapped blocks. These two age groups were chosen in order to compare rehearsing and nonrehearsing children; a spontaneous strategy of subvocal rehearsal typically emerges at around 7 years of age (Gathercole \& Hitch, 1993).

The letter and block recall tasks were selected for inclusion in the study because they represent the tasks used 
in relevant recent studies of adult short-term memory as assessments of verbal and visuospatial short-term memory (Henson et al., 1996; Smyth \& Scholey, 1996b). The procedures employed for letter and block recall were typical for each class of paradigm, but were not exactly matched in formal structure. In particular, the entire potential set of memory items is available to the child at recall in the block recall but not the letter recall task; as noted, some recent findings suggest that this differential degree of item availability may falsely give the appearance of task differences across the two domains (Farrand \& Jones, 1996). The lack of absolute equivalence in the formal structure of the letter and block recall tasks is considered later in the context of findings from the present study.

On the basis of previous work on both adults' memory for serial order and the developmental analysis of shortterm memory, two principal theoretical issues were addressed in the present study. The first issue concerns whether children's performance on tests of verbal and visuospatial short-term memory is served by common or distinct memory processes. Individual differences in children's abilities to recall verbal and visuospatial material were assessed in order to determine whether performance on the two domains of memory task is correlated (suggesting shared mechanisms) or independent of each other (indicating separate memory systems). At a more detailed level, the serial position functions, migration gradients, and serial order errors were compared in the letter and block recall tasks. The view that common mechanisms serve serial recall of both verbal and visuospatial material would be directly supported if it is found that the two tasks yield highly similar recall characteristics.

Whether the relationship between children's performance on verbal and visuospatial serial memory tasks changes qualitatively with development was the second general theoretical issue addressed in this study. Since this issue has not been the topic of systematic investigation to date, strong predictions about likely patterns of findings cannot be made. However, one possibility is that prior to the emergence of subvocal rehearsal (i.e., in the 5-year-old group), common general-purpose processes are used to maintain serial order in verbal and visuospatial memory tasks. If this is the case, the children's performance on the two domains of memory task should be significantly associated. Subsequently (at age 8 ), the dependence on an active rehearsal strategy may lead to the emergence of a dissociation between verbal and visuospatial memory performance, which would be characterized by independence on performance on the verbal and visuospatial tests. This study also provided the opportunity to investigate whether rehearsal is associated with a characteristic profile of serial order performance by comparing nonrehearsing and rehearsing children. The occurrence of distinctive recall features (e.g., in serial position functions or subtypes of serial order errors) only in the 8-year-old group on the verbal memory tasks would indicate that the features are themselves products of the rehearsal strategy.

\section{METHOD}

\section{Participants}

Fifty-nine children from two local primary schools took part in the study ( 27 girls and 32 boys). The younger children $(n=28)$ had a mean age of 5.7 years $(67.17$ months, $S D=2.59$ months, range = 63-71 months). The older group ( $n=31)$ had a mean age of 8.8 years (104.1 months, $S D=2.15$ months, range $=100-107$ months). No child was known to have any uncorrected sensory impairment, and in all cases, English was the only language spoken at home.

\section{Measures and Procedure}

All children were tested individually during school hours in a quiet room in the school, in two testing sessions separated on average by 2 days. Five measures were administered to each child; data from three of these measures are reported here. These included two experimental serial recall tasks plus an additional measure of verbal short-term memory-a digit span task.

Serial recall of letters. In this test, two sets of 10 lists of consonants were presented auditorily to the child. The two sets of lists varied in length, and the pairs of list lengths differed across the two age groups: The 5-year-olds received lists of four and five items, whereas the 8-year-old group received five- and six-item lists. Lists were drawn without replacement from the following pool of nine letters: $M, J, Q, R, K, H, X, Y, V$. Each list of letters was spoken aloud by the experimenter clearly, in an even tone, to the child at the rate of one letter per second. The children were instructed to listen carefully to each list and then to repeat it in exactly the same order. The child's response on each trial was recorded by the experimenter.

Both sets of lists were presented during the same session, although not directly following each other. The letter recall task was presented before the block recall task.

Serial recall of blocks. The child was seated in front of a black wooden board $(23 \times 28 \mathrm{~cm})$ on which were attached nine black cubes (each $3 \mathrm{~cm}$ ) in a nonsymmetrical arrangement following Isaacs and Vargha-Khadem (1989). The experimenter instructed the child to watch while she tapped out a pattern on the blocks, touching one block after another in a spatially unpredictable sequence in which the same block was never tapped twice. The child was then asked to repeat the pattern by touching each of the blocks in the same order. As in the serial recall of letters task, 10 trials were administered to each child at each list length and two list lengths were tested (four and five for the 5-year-old children, five and six for the 8 -year-old children). The experimenter recorded the sequences of blocks tapped by the children on each trial

Digit span. Children's digit span was measured for the purpose of having an additional measure of verbal memory for inclusion in our correlational analyses. On each trial of this test, the experimenter spoke aloud an unpredictable sequence of digits at the rate of one item per second; the child's task was to repeat the digits back in the same order. Initially, recall of two-digit sequences was tested. At this and successive list lengths, four lists were available for testing. However, if the child correctly recalled the first three lists at a particular length, the fourth list was not administered and the next block of digit lists increased in length by one. The number of the digits in each list then increased by one item every successive four lists. Testing stopped when two or more lists at a particular length were recalled incorrectly. Two measures were taken from this test--the child's digit span (i.e., the maximum number of digits correctly recalled in sequence) and the total number of lists correctly recalled.

\section{RESULTS}

\section{Serial Recall}

The performance of each child on the letter recall and block recall tasks was scored in two ways: the number of items (letters or blocks) recalled in the same serial posi- 
tion at recall as at input, and the number of lists in which all of the items were correctly recalled, in the correct serial order. Mean scores for the 5-and 8-year-olds on the block and letter recall tasks are shown in Table 1, for the different memory list lengths administered.

For both the item and list recall measures, performance was generally better on the letter than the block recall task at comparable list lengths, and this advantage to the letter recall over the block recall task appeared to be more pronounced in the older age group. However, since the two tasks were not strictly equivalent to each other in formal structure, particularly with respect to the greater item availability at recall for the block than for letter tasks, direct comparisons of levels of recall performance across the two tasks were not appropriate. Separate analyses of variance (ANOVAs) were therefore performed on the data for each task (letters or blocks) and also for both the items-correct and lists-correct measures.

The two age groups differed in the lengths of the lists they received in each task, with the younger group receiving four- and five-item lists and the older group receiving five- and six-item sequences, so direct comparisons across age groups were possible only for the five-item lists in each case. For each of the comparisons of the 5and 8-year-old children on the five-item lists, significant age effects were found for the letter recall items-correct measure $\left[F(1,57)=23.008, M S_{\mathrm{e}}=107.526, p<.001\right]$, for the letter recall lists-correct measure $[F(1,57)=26.698$, $\left.M S_{\mathrm{e}}=7.792, p<.001\right]$, for the block recall items-correct measure $\left[F(1,57)=17.451, M S_{\mathrm{e}}=98.611, p<.001\right]$, and for the block recall lists-correct measure $[F(1,57)=$ $\left.15.816, M S_{\mathrm{e}}=7.029, p<.001\right]$. In each case, these terms reflect substantially better accuracy of serial recall at both the item and list level for the older age group.

Further analyses were performed on the scores for each age group on the two list lengths on which children were tested in the letter recall and block recall tasks. Unsurprisingly, significantly poorer performance on the longer list length was found in each case. Consider first the outcomes of the ANOVAs performed on the data from the 5 -year-old group. Significant effects of list length were found for the letter recall items-correct measure $[F(1,27)$

Table 1

Mean Recall Accuracy in Serial Recall of Letters and Blocks as a Function of List Length and Age Group

\begin{tabular}{|c|c|c|c|c|c|c|c|}
\hline \multirow[b]{3}{*}{ List Length } & \multicolumn{7}{|c|}{ Age Group } \\
\hline & \multicolumn{4}{|c|}{5 Years } & \multicolumn{3}{|c|}{8 Years } \\
\hline & Item* & $S D$ & List ${ }^{\dagger}$ & $S D$ & Item* & List $†$ & $S D$ \\
\hline
\end{tabular}

$\begin{array}{ccccccccc}4 & 3.4 & .63 & 6.9 & 2.6 & - & - & - & - \\ 5 & 2.9 & 1.1 & 3.1 & 2.4 & 4.2 & .9 & 6.9 & 3.1 \\ 6 & - & - & - & - & 3.8 & 1.3 & 3.5 & 2.7\end{array}$

\begin{tabular}{rcccccccc}
\multicolumn{8}{c}{ Blocks } \\
4 & 3.1 & 0.6 & 6.0 & 4.4 & - & - & - & - \\
5 & 2.4 & 1.0 & 1.9 & 2.2 & 3.5 & 0.9 & 4.7 & 3.0 \\
6 & - & - & - & - & 2.9 & .9 & 1.3 & 1.8 \\
\hline
\end{tabular}

*Mean number of items recalled in correct serial position.

${ }^{+}$Mean number of lists correctly recalled $\left.=10.028, M S_{\mathrm{e}}=31.976, p<.01\right]$, for the letter recall listscorrect measure $\left[F(1,27)=88.292, M S_{\mathrm{e}}=2.272, p<\right.$ $.001]$, for the block recall items-correct measure $[F(1,27)$ $\left.=12.555, M S_{\mathrm{e}}=51.347, p<.01\right]$, and for the block recall lists-correct measure $\left[F(1,27)=65.506, M S_{\mathrm{e}}=\right.$ $3.605, p<.001]$. The outcomes of the corresponding analyses performed on the scores of the 8-year-old children were as follows: for letter recall items-correct measure $\left[F(1,30)=7.759, M S_{\mathrm{e}}=29.437, p<.01\right]$; for the letter recall lists-correct measure $\left[F(1,30)=66.124, M S_{\mathrm{e}}=\right.$ $2.689, p<.001]$; for the block recall items-correct measure $\left[F(1,30)=13.989, M S_{\mathrm{e}}=36.532, p<.001\right]$; and for the block recall lists-correct measure $[F(1,30)=59.779$, $\left.M S_{\mathrm{e}}=2.918, p<.001\right]$.

These analyses establish expected developmental increases in serial recall performance across the 5- and 8year-old groups as well as diminished performance within each age group at the longer lists lengths.

\section{Digit Span}

Two measures of performance were obtained from each child on the digit span task. The first measure was span, which was the highest list length at which the child correctly recalled two lists. Mean span scores were 4.0 $(S D=.54$, range $=3-5)$ at 5 years, and $5.2(S D=1.1$, range $=3-8)$ at age 8 . The second measure was number of lists correct; mean scores were 12.5 at 5 years $(S D=$ 2.3 , range $=8-17)$ and 17.6 at age $8(S D=4.1$, range $=$ 10-28). The higher recall scores for the 8- than for the 5-year-old children were highly significant both for span $\left[F(1,57)=27.886, M S_{\mathrm{e}}=.752, p<.001\right]$ and for lists correct $\left[F(1,57)=36.093, M S_{\mathrm{e}}=11.259, p<.001\right]$. Note that as a consequence of the restricted range of the span scores in the younger group in particular, the lists-correct score was used as the principal digit span measure in all remaining analyses to be reported.

\section{Correlations Between the Principal Measures}

One of the principal aims of the study was to investigate the interrelationships between verbal and visuospatial short-term memory measures in the 5- and 8year-old children in order to determine whether common or distinctive memory processes serve the two types of task. To this end, correlation coefficients were computed between the measures obtained from the three serial memory tasks (letter recall, block recall, and digit span). Note that in the analyses reported, serial recall itemscorrect scores were used. Corresponding analyses using the lists-correct measure were also conducted and yielded corresponding patterns of results.

Table 2 shows the correlation matrix obtained for the scores from the 5-and 8-year-old groups. For the 5-yearolds, all three verbal measures (serial recall with fourand five-item lists, and digit span) were significantly correlated with each other, with coefficients ranging between .46 to .63 ( $d f=26, p<.01$ and $p<.001$, respectively). In contrast, the four-item length block recall measure was not correlated with any other measure. Block recall for five-item lists scores were, however, highly associated with 
Table 2

Correlations Between Measures for 5- and 8-Year-Old Groups

\begin{tabular}{|c|c|c|c|c|c|c|c|c|c|c|c|c|c|}
\hline & \multicolumn{6}{|c|}{5 Years } & & \multicolumn{6}{|c|}{8 Years } \\
\hline & 1 & 2 & 3 & 4 & 5 & 6 & & 1 & 2 & 3 & 4 & 5 & 6 \\
\hline 1 Letter recall 4 & 1 & $.63^{*}$ & $.46^{*}$ & .29 & .30 & .05 & 1 Letter recall 5 & 1 & $.69^{*}$ & $.70^{*}$ & -.04 & .22 & -.20 \\
\hline 2 Letter recall 5 & & 1 & $.50^{*}$ & .09 & $.65^{*}$ & .13 & 2 Letter recall 6 & & 1 & $.72 *$ & -.02 & .04 & -.03 \\
\hline 3 Digit span score & & & 1 & -.14 & .12 & -.06 & 3 Digit span score & & & 1 & -.20 & .04 & -.32 \\
\hline 4 Block recall 4 & & & & 1 & .23 & .04 & 4 Block recall 5 & & & & 1 & $.59^{*}$ & -.01 \\
\hline 5 Block recall 5 & & & & & 1 & .06 & 5 Block recall 6 & & & & & 1 & .08 \\
\hline 6 Age & & & & & & 1 & 6 Age & & & & & & 1 \\
\hline
\end{tabular}

$* p<.01$.

letter recall scores at the same length $(r=.65, d f=26$, $p<.001)$. Digit span was significantly more highly correlated with letter recall than with block recall for both four- and five-item lists $(t=2.98, d f=25, p<.01$ and $t=2.75, d f=25, p<.01$, respectively). The pattern with respect to letter recall was less clear. Letter recall was not significantly more highly correlated with digit span than with block recall at either list length $(d f=25, p>$ .05 in each case).

The independence of scores on the short version of the block recall task (list length 4) from all verbal memory measures is consistent with the view that verbal memory and visuospatial short-term memory are served by distinct memory subsystems. The nonsignificant association between the two list lengths on the block recall task and the sizable link between performance on the longer lists in the block task and scores on the letter lists of the same length are, however, more puzzling. It is notable that scores on the five-item lists in both the block recall and the letter recall tasks were low: Only $58 \%$ of the letters were recalled in the correct position at this length, and $48 \%$ of the blocks. The very high association between performance on the lengthiest versions of these two tasks may reflect the differential abilities of the children to meet the demands of the supra-span lists in the two domains, possibly due to the employment by some children of a general strategy that was appropriate for use in recalling both the letter and the block sequences. It is at present unclear what this strategy may constitute, but it could be as simple as selectively attending to just one part of the recall sequence as a means of maintaining at least some level of accuracy in recall. This kind of general strategy would serve the children equally well on both memory tasks. For two reasons, this strategy cannot be verbal rehearsal: First, it is tapped in the block recall task, and second, there is no evidence for this strategy in the digit span task, despite previous evidence that rehearsal may emerge earlier for digits than for other kinds of verbal memory list (Gathercole \& Adams, 1994).

Correlation coefficients obtained with the 8-year-old children show that the two letter recall measures and digit span scores were again strongly associated with each other, with correlation coefficients in excess of 69 in each case $(d f=29, p<.001)$. Scores on the two measures of the block recall task were highly associated with each other $(r=.59, d f=29, p<.001)$, but unrelated to all three ver- bal memory measures ( $d f=29, p>.05$ in each case). Digit span was significantly more highly correlated with letter recall than with block recall for the five- and sixitem lists $(t=4.61, d f=28, p<.001$ and $t=3.96, d f=$ $28, p<.001$, respectively). Letter recall was found to be significantly more highly correlated with digit span than with block recall in this age group (for five-item lists, $t=3.29, d f=28, p<.01$; and for six-item lists, $t=2.75$, $d f=28, p<.01$ ).

These results are broadly in line with the view that tests of verbal and visuospatial memory are served by distinct memory systems. Scores on the letter recall and digit span measures were closely correlated with each other at both ages and were independent of block recall scores except for the longest list length in the younger age group, as noted.

\section{Serial Position}

The mean number of items correctly recalled at each serial position was calculated for each age group for the two serial recall tasks; these results are shown in Figure 1. Two-way ANOVAs with task and serial position as factors were conducted on data obtained at each list length, for each age group. The effects of primacy and recency were investigated separately. Primacy effects were calculated with a two-way ANOVA with all list positions except for the final position included. Recency effects were investigated by including only the final and penultimate list positions in the analysis (Positions 3 and 4 for the four-item lists, 4 and 5 for the five-item lists, and 5 and 6 for the six-item lists). This represents a common method for comparing the magnitude of recency across different conditions (see, e.g., Campbell, Dodd, \& Brasher, 1983; Gathercole, 1986; Nairne \& Walters, 1983) and is particularly appropriate in the present case because asymptotically low levels of recall typically occurred at the penultimate position.

In examining primacy effects, the two-way ANOVA on data from the 5-year-old group recalling four-item lists revealed a main effect of serial position $[F(2,54)=21.557$, $\left.M S_{\mathrm{e}}=.916, p<.001\right]$, although both the main effect of $\operatorname{task}\left[F(1,27)=1.499, M S_{\mathrm{e}}=9.930, p>.05\right]$ and the interaction between task and serial position $[F(2,54)=$ $\left.2.864, M S_{\mathrm{e}}=.887, p>.05\right]$ were nonsignificant. Comparisons of the means for the initial three serial positions established that the main effect of serial position was due 

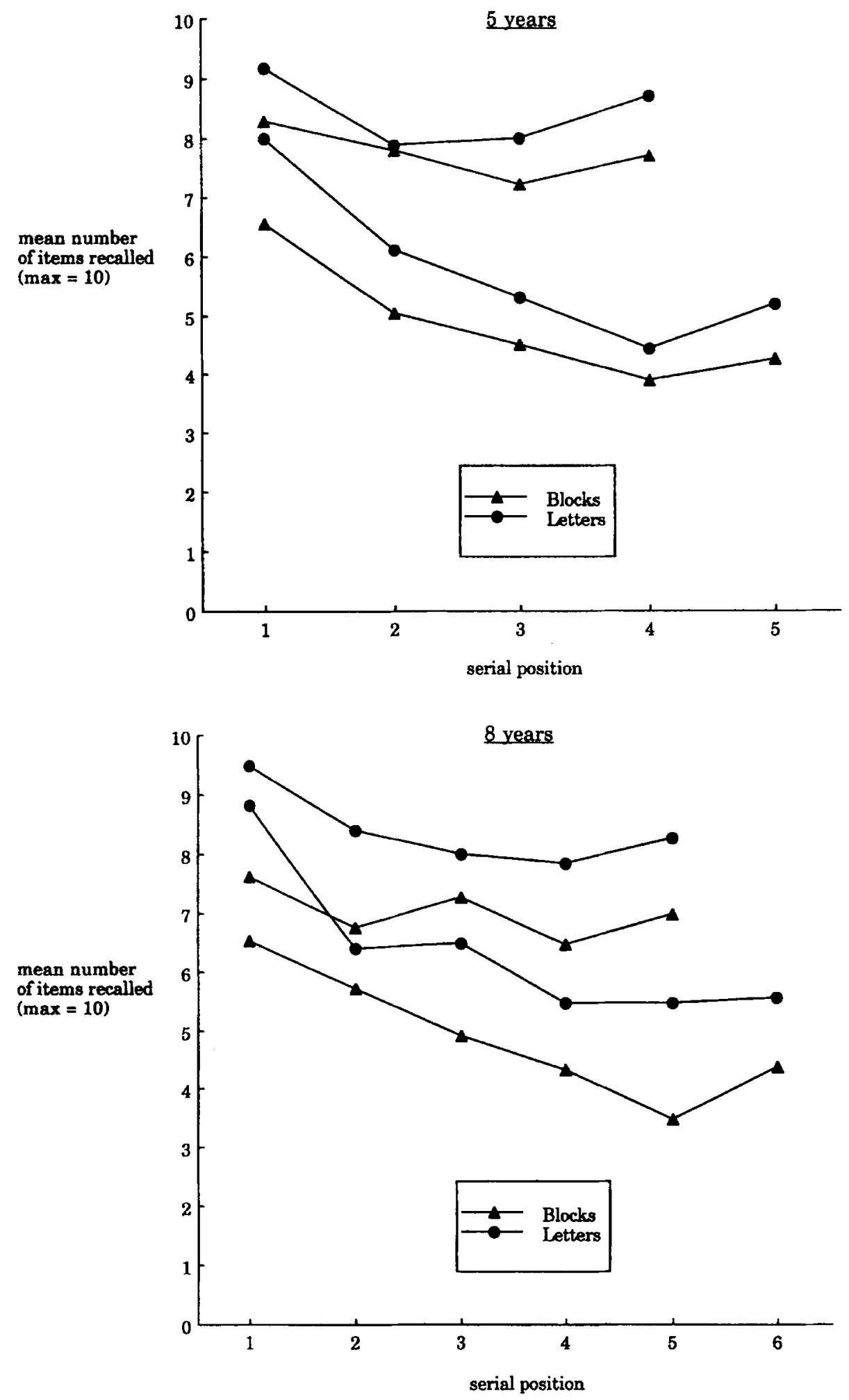

Figure 1. Mean number of items correctly recalled as a function of age, task, and list length.

to significantly better recall of items at Serial Position 1 than at subsequent serial positions (an advantage of initial position over Position 2 of 1.28 for letters and 0.50 for blocks). When final and penultimate serial positions were compared for this age group for recall of the shorter lists, significant effects of task $\left[F(1,27)=4.315, M S_{\mathrm{c}}=\right.$ $5.173, p<.05]$ and serial position $[F(1,27)=8.036$, $\left.M S_{\mathrm{e}}=1.284, p<.01\right]$ were found. Recall of both letters 
and blocks was better at the final position than at the penultimate position, although as found in the previous analysis, performance was better on the letter recall task at all serial positions. Thus, recall in both the letter and block recall tasks was characterized by relatively strong primacy effects and recency effects for this age group, in the shorter list length condition.

Similar results were found for recall of five-item lists for the 5-year-olds, although as Figure 1 reveals, performance declined more steeply across initial serial positions than when four-item lists were recalled. Primacy effects were investigated with a two-way ANOVA with serial position as one factor (Positions 1-4) and task type as the second factor. Significant effects were obtained for both serial position $\left[F(3,81)=63.722, M S_{\mathrm{e}}=1.550\right.$, $p<.001]$ and task $\left[F(1,27)=6.595, M S_{\mathrm{e}}=7.896, p<\right.$ $.05]$. These reflect the better recall of letters than of blocks, and of items at initial than later positions, respectively. The interaction between task and serial position was nonsignificant $\left[F(3,81)=1.595, M S_{\mathrm{e}}=1.396, p>.05\right]$. A corresponding two-way ANOVA in which Positions 4 and 5 constituted the two levels of serial position yielded only a main effect of serial position $[F(1,27)=5.186$, $\left.M S_{\mathrm{e}}=1.654, p<.05\right]$ : Performance was superior at Position 5 as opposed to 4 in both tasks. The nonsignificant terms were as follows: task $\left[F(1,27)=3.064, M S_{\mathrm{e}}=\right.$ $4.898, p>.05]$ and task and serial position $[F(1,27)=$ $\left.1.207, M S_{\mathrm{e}}=.895, p>.05\right]$.

A two-way ANOVA performed on the scores of the 8year-old group for the five-item lists as a function of the first four list positions and task type yielded significant main effects of task $\left[F(1,30)=9.340, M S_{\mathrm{e}}=13.221\right.$, $p<.01]$ and serial position $\left[F(3,90)=13.024, M S_{\mathrm{e}}=\right.$ $1.665, p<.001]$, with no significant interaction between the two factors $\left[F(3,90)=2.420, M S_{\mathrm{e}}=1.526, p>.05\right]$. Inspection of means again reveals better recall of items in the letter task at all Serial Positions than in the block recall task, with items at initial positions recalled better than those at subsequent positions. A two-way ANOVA on scores at Serial Positions 4 and 5 in the two tasks yielded significant effects of task $\left[F(1,30)=5.443, M S_{\mathrm{e}}=10.206\right.$, $p<.05]$ and serial position $\left[F(1,30)=7.835, M S_{\mathrm{e}}=\right.$ $.866, p<.01]$, but no interaction between the two factors $[F(1,30)<1]$.

Finally, the recall data from the older group on the sixitem lists were analyzed. In the analysis of the scores as a function of preterminal serial position (1-5) and task type, significant main effects were found of both task $\left[F(1,30)=9.921, M S_{\mathrm{e}}=18.264, p<.01\right]$ and serial position $\left[F(4,120)=48.490, M S_{\mathrm{e}}=1.961, p<.001\right]$. These reflect superior performance on the recall of letters over blocks, and at initial over later serial positions, respectively. A significant interaction between task and serial position was also obtained $\left[F(4,120)=3.234, M S_{\mathrm{e}}=1.989\right.$, $p<.01]$ due to the greater primacy effect in recall of letters than blocks. In the corresponding analysis of scores at list length 6 as a function of final list position ( 5 and 6 ) and list type, an interaction between serial position and task type was also found $\left[F(1,30)=6.846, M S_{\mathrm{e}}=\right.$ $.678, p<.01]$ due to a greater recency effect in recall of blocks than of letters. Significant main effects were also obtained in this analysis for both task $[F(1,30)=7.072$, $\left.M S_{\mathrm{e}}=10.952, p<.01\right]$ and serial position $[F(1,30)=$ $\left.7.849, M S_{\mathrm{e}}=.925, p>.01\right]$

The recall data for the 8-year-old children at longer list lengths therefore reveal some differences in the serial position functions for the letter and block recall tasks. Letter lists showed enhanced recall of initial list items and diminished recall of final items relative to block sequences. In three out of four cases (8-year-olds recalling five-item lists and 5-year-olds recalling both list lengths) the serial position functions were very similar for letter and block recall, but it seems unlikely that the different serial position functions associated with letter and block recall reflect the operation of different mechanisms in the two cases. Rather, it is more probable that the distinct serial position functions obtained for the older age group resulted from different strategies for coping with supraspan six-item memory lists in the two-list conditions. Specifically, the children appear to have prioritized recall of early over late items in letter recall, but late over early items in block recall. In adults, at least, volitional changes in encoding strategy have been shown to result in tradeoffs across primacy and recency portions of the serial position curve similar to those obtained here (Hockey, 1973).

In summary, children of both ages were better at sequences of letter names than of blocks, but the serial position functions obtained across the two tasks were markedly similar. In each case, there were strong primacy effects and somewhat weaker recency effects.

\section{Error Classification}

The nature of the errors made in the serial recall of letter and block sequences was also analyzed. Each item in the list was categorized according to whether it was correctly or incorrectly recalled on the basis of its accuracy and position. For example, a list ABCDE recalled as ABCE would be scored as three correct items (correct letters in the correct serial positions) plus two errors (the omission of an item and the movement of an item). Thus, the total output from each child was scored relative to the corresponding input, allowing more than one error to be scored for a particular item in the list as, for example, in the case of the omission of an item and the inclusion of a nonlist item. All errors were analyzed in terms of the total output for each child, corresponding to the number of items correctly recalled in the correct serial position plus errors.

The principal analyses focused on the serial position functions and the distributions of different kinds of error across the two tasks. Before presenting those data and the relevant analyses, we must consider the variability found in the length of the children's recall sequences since this has consequences for interpretation of the migration data presented later in this section. On some trials in each of the serial recall tasks, the lists of items re- 
called by the children were either too short or too long. This is one of the seemingly inevitable difficulties that arise when young children are asked to recall serially presented lists by spoken report, a difficulty that can be avoided in serial recall tasks with adult participants by requiring them to write down the memory lists. Unfortunately, written recall is not an appropriate method for use with young children. The proportions of lists on which the correct number of items, too few items, and too many items were recalled by the children are shown in Table 3.

The proportion of lists in which an incorrect number of items was recalled increased from an average of $10 \%$ to $32 \%$ for the longer list in each condition. Incorrect recalls with too few items were more common than were recalls with too many items in both recall tasks and for both ages, although the extent of this bias toward shorter list lengths varied according to task. The short list lengths were approximately four times more common than long list responses for the letter recall tasks. This bias was attenuated somewhat for the block recall task, in which participants recalled only twice as many short as long lists. There were no notable differences in the deviations from correct list lengths between the 5- and 8-year-old children. For the purposes of the more detailed analyses of serial recall performance described next, data from both correct and incorrect list length trials were included.

The movement of items from the input position in the original list to the output position in the child's protocol was classified following Henson et al. (1996) and Smyth and Scholey (1996b). Illustrative migration data obtained from the 5-year-old group at the longer list length (five items) are provided in Figure 2. This shows the proportion of items recalled in the letter and block recall tasks at each output position as a function of their input position. The taller bars at each input position represent the proportion of items recalled in the correct serial position, with the smaller bars indicating the items that were recalled in incorrect serial positions. Similar migration gradients were observed for short and long lists, for letter and block recall, and for both age groups.
Items that were recalled at incorrect positions in the output list produce a strikingly regular pattern, with the greatest proportion of order errors being recalled at the positions adjacent to the correct position. As the distance from the correct position increases, the proportion of items recalled decreases, in line with previous findings reported by Henson et al. (1996) and Smyth and Scholey (1996b). In the present data, the greatest proportion of order errors falls at the position immediately preceding the correct position, in contrast to the largely symmetrical migration functions of those earlier studies. The negative skew present in our data but not in studies of adult serial recall seems likely to be due to the increased frequency of recall of lists that are too short in this participant group (constituting $34 \%$ and $25 \%$ of list letter and block lists, respectively), as reported above.

Summary migration gradients were calculated for the two age groups on the two tasks at each list length in which the total proportion of items recalled at each distance from the input position was calculated, regardless of direction of distance. The data are summarized in Figure 3. The distribution of errors is strikingly similar for both letter and block recall at both ages: In all cases, items not recalled in their original input position were more likely to be recalled in positions close to than distant from the target position.

The errors that participants made on the two recall tasks were also categorized as either order or item errors, and then further subclassified. Three types of order errors were identified. Transpositions are cases in which two items switch places either adjacently or with one or more intervening item between them. Examples of this error type are provided by incorrect recalls of ACBDE or ADCBE following the target sequence $\mathrm{ABCDE}$. Relative errors are items recalled in incorrect serial positions in which their position was correct relative to the item that came before them. For example, if the original list was $\mathrm{ABCDE}$ but the sequence ACDEB was recalled, items D and $E$ would be classified as relative errors because they were in the correct position relative to the item that pre-

Table 3

Percentage of Lists Recalled by Deviation From Correct List Length, as a Function of Age, Task, and List Length

\begin{tabular}{ccccccccc}
\hline & & \multicolumn{5}{c}{ Deviation From Correct List Length } \\
\cline { 3 - 8 } Age & Task & $\begin{array}{c}\text { Correct List } \\
\text { Length }\end{array}$ & $-2(+)$ & -1 & 0 & +1 & $+2(+)$ & $\begin{array}{c}\text { Ratio of } \\
\text { Deviations }\end{array}$ \\
\hline 5 & Letters & 4 & 1 & 4 & 92 & 3 & 0 & 1.67 \\
& & 5 & 10 & 24 & 61 & 5 & 1 & 5.67 \\
& $M$ & 5.5 & 14.10 & 76.5 & 4.0 & 0.5 & 4.33 \\
& \multirow{3}{*}{ Blocks } & 4 & 0 & 1 & 91 & 8 & 0 & 0.12 \\
& 5 & 2 & 23 & 70 & 5 & 0 & 5.0 \\
& & $M$ & 1.0 & 12.0 & 80.5 & 6.5 & 0 & 2.0 \\
& \multirow{3}{*}{ Letters } & 5 & 0 & 6 & 90 & 3 & 1 & 1.5 \\
& 6 & 4 & 20 & 73 & 3 & 0 & 8.0 \\
& & $M$ & 2 & 13 & 81.5 & 3 & 0.5 & 4.29 \\
& Blocks & 5 & 0 & 5 & 86 & 8 & 1 & 0.56 \\
& 6 & 1 & 19 & 69 & 11 & 0 & 1.82 \\
& & $M$ & 0.5 & 12.0 & 77.5 & 9.5 & 0.5 & 1.25 \\
\hline
\end{tabular}



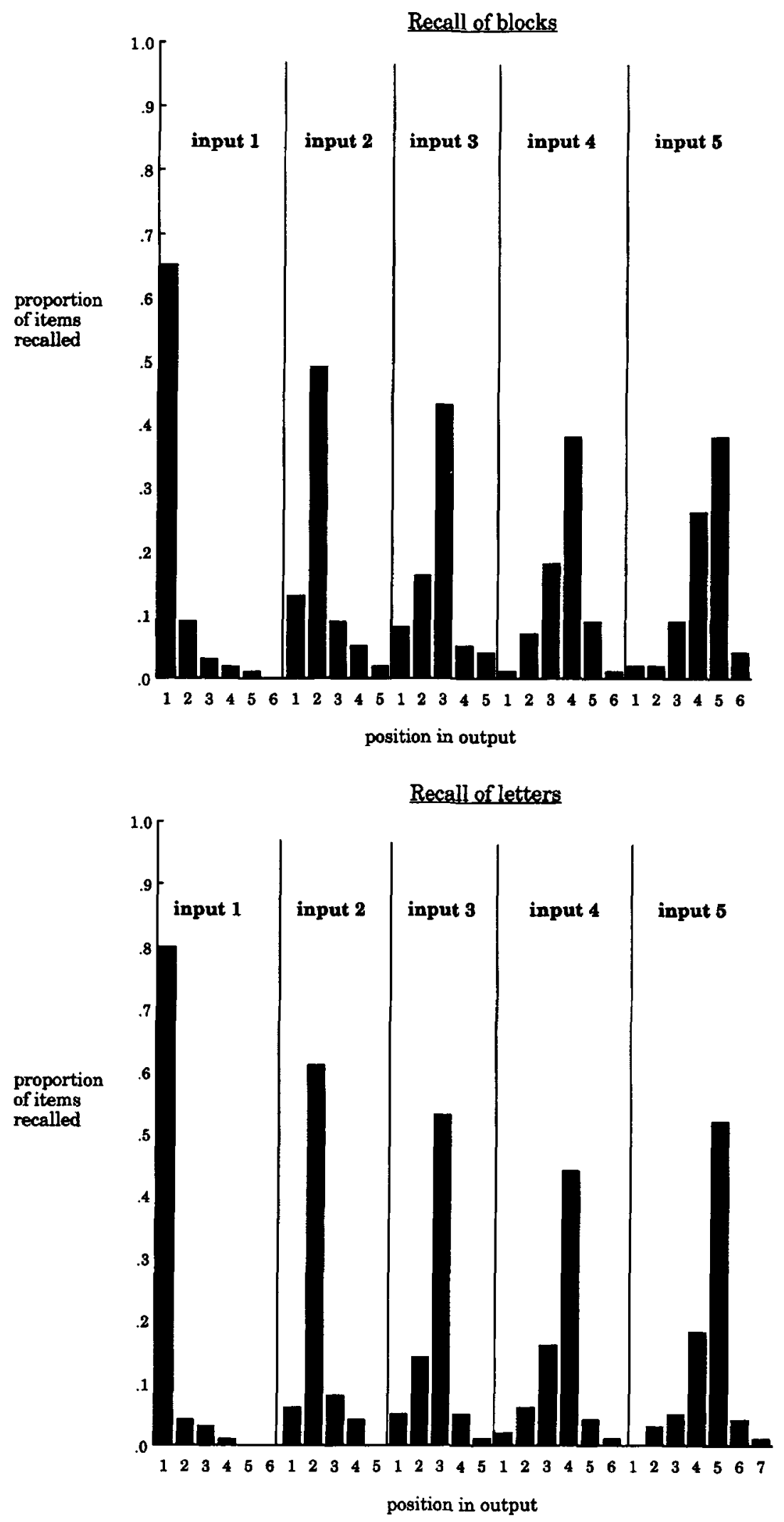

Figure 2. Proportion of items recalled at each output position as a function of age, task, and input position. 


\section{$\underline{5 \text { years }}$}

4-item lists

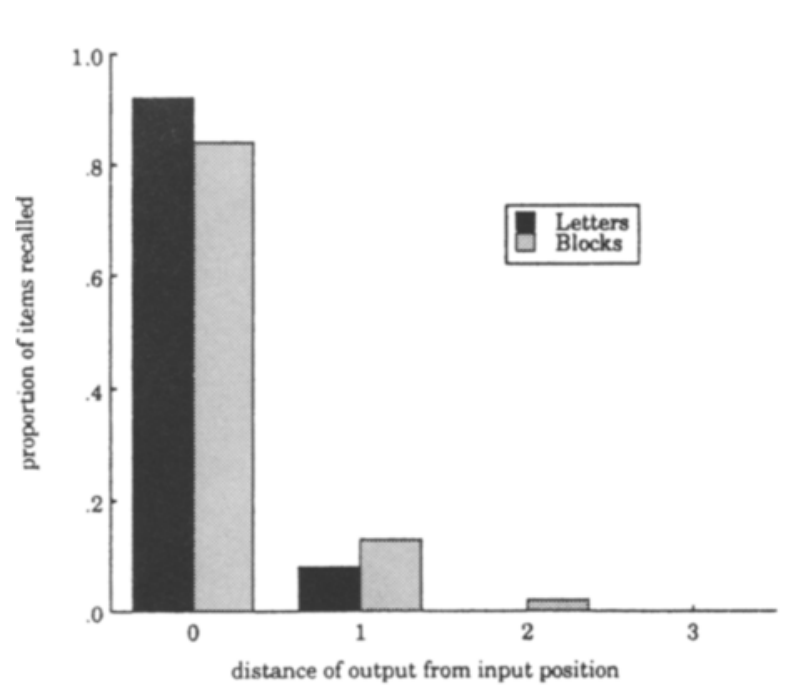

\section{$\underline{8 \text { years }}$}

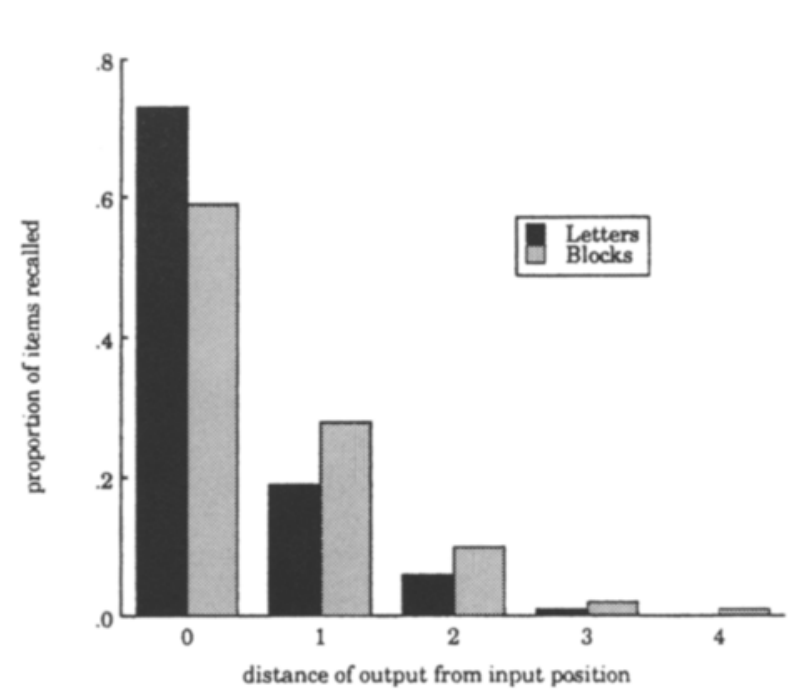

distance of output from input position

5-item lists
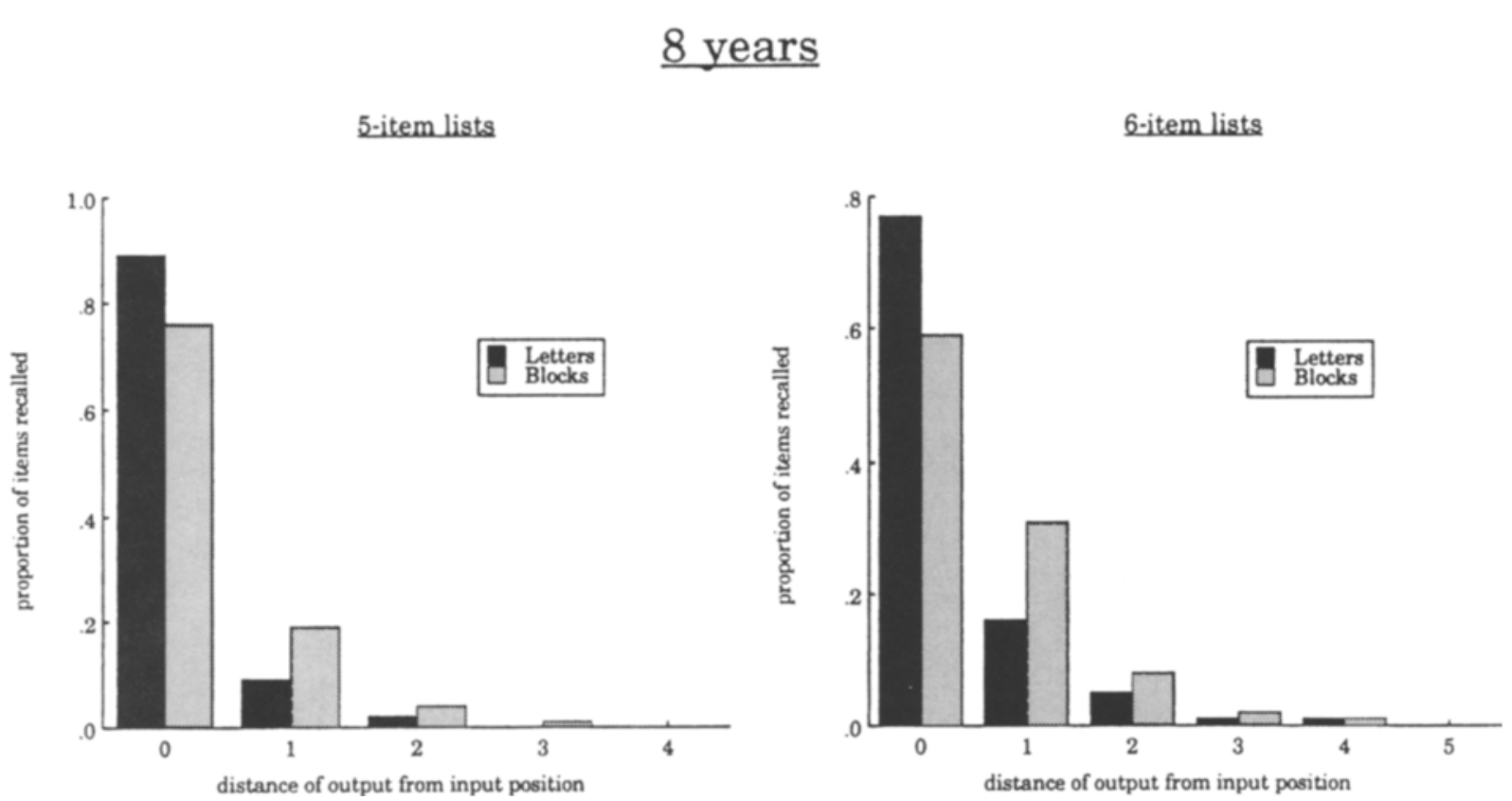

Figure 3. Proportion of items recalled as a function of distance from input position by age, list length, and task.

ceded them (C). Finally, migration errors occur when items are not recalled in the correct serial position but cannot be classified as transpositions or relative errors. An example of this would be if the child recalled ABECD instead of $A B C D E$.

Three types of item error were classified. Omission errors occur when items are missing from the recall protocol but have not been directly replaced by an item from outside the original list. So if the input list $A B C D E$ was recalled as ACDE or ACDEX, item B would be classified as an omission. In the first case, this omission led to the list being recalled at the wrong length, whereas in the second case, an item from outside the input was recalled although not in the same place as the item was lost. Itemsgained errors arise when items that are not in the input list are recalled. These items could be directly substituted for correct items, as in the case of incorrect recall $\mathrm{ABXDE}$, or randomly located novel items, as in the case of $\mathrm{ABCXD}$ 
(where this list would score as an omission of $\mathrm{E}$ and an item-gained at position 4). Repetition errors involve the repetition of an item at recall, as in the case of $A B C B E$. Repetition errors usually involve items that did appear in the input but can also include items-gained errors, as in the case of AXCDX.

Combining the data for the short and long list lengths, we calculated error type proportions for each age group and each of the letter and block recall tasks (see Table 4 for summary). The distributions of errors are largely consistent across age and recall task. In each case, the three error categories accounting for the greatest percentage of errors are migrations, omissions, and items-gained, each of which comprises between $16 \%$ and $29 \%$ of total errors. Repetitions account for the smallest proportion of total errors in all cases, between $4 \%$ and $8 \%$.

The distributions of error categories across recall task and age group were not, however, exactly equivalent: The three kinds of order error (migrations, transpositions, and relative errors) dominated for the block recall task, especially in the older age group, and greater proportions of item errors in the letter recall task were found in both age groups. In order to provide the basis for a systematic evaluation of the error profiles across task and age group, we calculated the proportion of the total errors made by each child assigned to each of the six principal error categories for each task as a function of age. These error proportion scores were then analyzed in a series of ANOVAs. In these analyses, the data from one 5and two 8-year-old children who made fewer than $5 \%$ errors were excluded.

In the 5-year-old group, order errors represented $45 \%$ of all errors in the letter recall task and $54 \%$ of errors in the block recall task; thus, item errors were more frequent than order errors in the letter recall task but the converse was true for the block recall task. For the 8-year-old children, $43 \%$ of errors made in letter recall were order errors, again showing a dominance of item errors; for block recall, the majority of errors $(61 \%)$ were order errors.

In order to establish whether the proportions of order and item errors varied significantly in the younger and older groups of children, we performed an initial one-way ANOVA on the proportion of order errors made as a function of age. The ANOVA performed on the data for the letter recall task indicated that there was no significant difference between the proportion of order errors made by the two age groups $\left[F(1,54)=.214, M S_{\mathrm{e}}=.024, p>\right.$
.05]. There was, however, a significantly greater proportion of order errors made in the block recall task by the older than by the younger children $[F(1,54)=5.879$, $\left.M S_{\mathrm{e}}=.012, p<.05\right]$.

The subcategories of order and item errors were analyzed in separate ANOVAs for each task. For the letter recall task, the proportions of the three categories of order error did not differ significantly with age for migrations $\left[F(1,54)=.072, M S_{\mathrm{e}}=.009, p>.05\right]$, transpositions $\left[F(1,54)=.001, M S_{\mathrm{e}}=.011, p>.05\right]$, or relative errors $\left[F(1,54)=.217, M S_{\mathrm{e}}=.009, p>.05\right]$. The proportions of migrations and relative errors in the block recall task did not differ between the two age groups $[F(1,54)=$ $.1 .144, M S_{\mathrm{e}}=.008, p>.05$, and $F(1,54)=.059, M S_{\mathrm{e}}=$ $.005, p>.05$, respectively]. However, a significantly greater proportion of transposition errors were made by the 8-year-olds than by the 5-year-olds in this task $[F(1,54)$ $\left.=.7 .336, M S_{\mathrm{e}}=.016, p<.01\right]$. The three types of item error were found to occur in similar proportions for both age groups in the letter recall task. The nonsignificant terms were for omissions $\left[F(1,54)=.818, M S_{\mathrm{e}}=.016\right.$, $p>.05]$, items gained $\left[F(1,54)=.709, M S_{\mathrm{e}}=.018, p>\right.$ $.05]$, and repetitions $\left[F(1,54)=.1 .673, M S_{\mathrm{e}}=.003, p>\right.$ $.05]$. This contrasted with the significant differences found between item error proportions in the block recall task in the two age groups. The 5-year-olds made significantly more omissions and items-gained errors than the 8-yearolds $\left[F(1,54)=5.003, M S_{\mathrm{e}}=.007, p<.05\right.$, and $F(1,54)$ $=.5 .085, M S_{\mathrm{e}}=.006, p<.05$, respectively], but the older children made a greater proportion of repetition errors on this task $\left[F(1,54)=3.916, M S_{\mathrm{e}}=.001, p<.05\right]$.

Thus, differences in the proportions of the error categories made by the younger and older children were found for the block recall task, but not the letter recall task. The older children made more transposition errors when recalling the sequences of blocks, in line with the finding that this age group made significantly more order errors overall in block recall. The 5-year-olds, on the other hand, made a greater number of item errors in the block recall task, particularly omissions and items-gained errors.

The detailed analyses of errors on the two serial recall tasks reported in this section reveal both commonalities and differences in the error patterns characteristic of the verbal task (letter recall) and the visuospatial task (block recall), and of the older and younger children. The principal differences related to the frequency of order errors. In the block recall task, these errors were more common

Table 4

Proportion of Each Error Type Made as a Function of Age and Task

\begin{tabular}{|c|c|c|c|c|c|c|c|}
\hline \multirow[b]{3}{*}{ Age } & \multirow[b]{3}{*}{ Task } & \multicolumn{6}{|c|}{ Error Type } \\
\hline & & \multicolumn{3}{|c|}{ Order Errors } & \multicolumn{3}{|c|}{ Item Errors } \\
\hline & & Migrations & Transpositions & $\begin{array}{c}\text { Relative } \\
\text { Errors }\end{array}$ & Omissions & Items & $\begin{array}{c}\text { Repetitions } \\
\text { Gained }\end{array}$ \\
\hline \multirow[t]{2}{*}{5} & Letters & .23 & .10 & .10 & .27 & .25 & .05 \\
\hline & Blocks & .29 & .15 & .10 & .20 & .22 & .04 \\
\hline \multirow[t]{2}{*}{8} & Letters & .23 & .10 & .09 & .25 & .25 & .08 \\
\hline & Blocks & .27 & .24 & .10 & .16 & .17 & .06 \\
\hline
\end{tabular}


for the older children. In contrast, item errors predominated for the younger children.

\section{DISCUSSION}

The purpose of this study was to investigate whether children's immediate memory for verbal and visuospatial material draws on the same or dissociable memory systems and processes. Two recall tasks were contrasted, memory for letter names (verbal short-term memory) and for block sequences (visuospatial short-term memory), in 5-and 8-year-old children. Evidence for both common and distinct contributions to recall of material in the two different domains was found. Individual differences analyses revealed that children's scores on the letter and block recall tasks were largely independent of each other, consistent with findings from experimental studies with adults (Smyth \& Scholey, 1996a) and neuropsychological patients (e.g., Hanley et al., 1991; Vallar \& Baddeley, 1984). These findings suggest that fundamentally different memory systems underpin verbal and visuospatial memory, in line with the working memory model (Baddeley, 1986; Baddeley \& Hitch, 1974). At a more detailed level, however, the verbal and visuospatial tasks yielded broadly similar patterns of error in terms of serial position, migration patterns, and the distributions of different error types. These aspects of the results indicate that tasks requiring the reconstruction of serial order may call on common processes, irrespective of whether the storage medium is verbal or visuospatial memory.

The letter and block recall tasks yielded similar serial position functions, particularly for the 5 -year-old children. Shallow asymmetric serial position curves were found across both tasks, with primacy effects that extended over several list positions and weaker recency effects. These data fit well with other recent findings that when verbal and visual memory tasks are matched with respect to their serial order requirements, they yield highly similar serial position profiles (Jones et al., 1995; Smyth \& Scholey, 1996b).

The patterns of list item movement were virtually identical in letter and block recall. When items were recalled in their incorrect positions in the output sequence, they were much more likely to appear in positions adjacent than nonadjacent to the target. This migration gradient has been observed in adult data recently in a letter recall task by Henson et al. (1996) and in block recall by Smyth and Scholey (1996b). The present data from children were rather more asymmetric than the migration gradients reported in the adult studies, with wrongly located items being more frequently output at the position prior to the correct position in the list than at the position following. This negative skew to the distribution probably reflects the greater frequency with which children recall lists shorter than the original input sequences, although direct data from the adult studies that bear on this issue are not available to support a systematic comparison. But most importantly for present purposes, the migration gradients were very similar in the verbal and visuospatial tasks.
There were both similarities and differences in the types of serial recall errors made in the letter and block recall tasks. Each error response was classified as either an item error (e.g., when an item in the presented list was not recalled at all or when an item that was not in the original list was recalled) or an order error (e.g., when an item from the input list was recalled at an incorrect position). Each of these error categories was then categorized further. In many respects, error patterns corresponded closely across the verbal and visuospatial tasks. Item and order errors were common in both cases. For order errors, migrations of items across positions were more frequent than pairwise transpositions of items, and items recalled in the correct position relative to the previous item but mislocated in the output sequence were relatively uncommon. For item errors, omissions of items in the input list and items gained from outside the input list were equally frequent, and repetitions were relatively uncommon.

There were, however, some differences in the balance of the distributions of the different error categories across the letter and block tasks. Order errors dominated block recall in the 8-year-old group, whereas there were more item than order errors in the letter recall task. One possibility is that these differences in the relative frequencies of order and item errors across the two recall tasks arise because distinct memory mechanisms or processes are operating to extract serial order in the two cases. This account, however, fails to accommodate the many similarities in the distributions of error categories across the two tasks, in line with previous findings across studies of adult serial recall of verbal and visuospatial stimuli (Henson et al., 1996; Smyth \& Scholey, 1996b).

We favor instead the view that the two tasks, letter and block recall, are not different in terms of how serial order is maintained in memory. The shift in the balance of item and order errors as the task domain changes from verbal to visuospatial seems more likely to reflect differences in the formal structure of the two tasks rather than differences in the processes operating to extract serial order information. The letter and block recall tasks differ in at least two important respects likely to influence the differential distribution of order and item errors (see also Farrand \& Jones, 1996). First, the experimental pool of items is visible to the child throughout presentation and recall in the block recall task, but not in letter recall. Second, although the letters to be recalled in both tasks have been selected from total experimental vocabularies of nine items, the letters are drawn from a potential pool of 26 items, and many children may have been unaware of the constrained stimulus set employed in the task. Both of these factors result in a larger pool of possible responses in the letter than the block task that should diminish the accuracy of item recall while leaving the burden of retaining order information unchanged. By this account, the shift in the balance of item and order errors in the block and letter recall tasks reflects the greater availability at recall of item information in the visuospatial task.

One of the aims of this study was to establish whether the relationship between children's verbal and visuo- 
spatial short-term memory performance changes in relation to the emergence of a subvocal rehearsal strategy, which typically occurs at around 7 years of age. Prior evidence that subvocal rehearsal is a strategic process that develops in middle childhood is available from a variety of sources (see Gathercole \& Hitch, 1993), including training studies in which rehearsal-associated phenomena emerge following rehearsal training in young children (Johnson, Johnson, \& Gray, 1987) and observational studies of lip movements during recall tasks with older children (Flavell et al., 1966). There was indeed some evidence for developmental change across the 5-and 8-year-old age groups. The serial position functions, migration patterns, and distribution of error types of the 5-year-old children were highly similar across the verbal and visuospatial tasks. In the older group, recall characteristics were generally similar across the two tasks with two exceptions: The 8-year-olds recalled more items at early list positions and fewer at the list-final position for the letter than the block sequences at the longest list lengths, and they made many more order than item errors in recall of blocks than letters. One interesting possibility is that these relatively minor but still notable differences in recall across the verbal and visuospatial tasks in the older children may be a consequence of the emergence of a subvocal rehearsal strategy for maintaining verbal material in short-term memory. It is, however, not at all clear how the use of a subvocal rehearsal strategy would result in the observed dominance of order over item errors in block recall. It may simply be the case that the larger proportion of order errors found in the block recall task in the 8-year-old group reflect the greater opportunity for order than item errors at longer list lengths using the block display, as noted.

Although the precise nature of the processes used to extract serial order information from verbal and visuospatial short-term memory has yet to be identified, several computational models are capable of simulating a range of recall phenomena, including the serial position and migration effects found here (Brown et al., 1997; Burgess \& Hitch, 1992; Henson et al., 1996; Lewandowsky \& Murdock, 1989). The contribution of the present study is to demonstrate within a single data set that in children, at least, these phenomena are strikingly similar in the verbal and visuospatial domains, despite independence in the overall levels of task performance across the two domains. Full theoretical accounts of serial recall performance therefore need to incorporate both domain-independent processes that can apply across input modalities and independent domain-specific memory systems that are subject to individual variation in functional capacities.

\section{REFERENCES}

BADDELEY, A. D. (1986). Working memory. Oxford: Oxford University Press.

Baddeley, A. D., \& Hitch, G. (1974). Working memory. In G. H. Bower (Ed.), Recent advances in learning and motivation (Vol. 8, pp. 47-90). New York: Academic Press.

BjoRK, E. L., \& Healy, A. F. (1974). Short-term order and item retention. Journal of Verbal Learning \& Verbal Behavior, 13, 80-97.
Brown, G. D. A., Preece, T., \& Hulme, C. (1997). Oscillator-based memory for serial order. Manuscript submitted for publication.

Burgess, N., \& Hitch, G. J. (1992). Towards a network model of the articulatory loop. Journal of Memory \& Language, 31, 429-460.

Burgess, N., \& HITCH, G. J. (1996). A connectionist model of STM for serial order. In S. E. Gathercole (Ed.), Models of short-term memory (pp. 51-72). Hove, U.K.: Psychology Press.

CAMPBell, R., DoDD, B., \& Brasher, J. (1983). The sources of visual recency: Movement and language in serial recall. Quarterly Journal of Experimental Psychology, 35A, 571-587.

CoNRAD, R. (1965). Order error in immediate recall of sequences. Journal of Verbal Learning \& Verbal Behavior, 4, 161-169.

CowaN, N., \& KaIL, R. (1996). Covert processes and their development in short-term memory. In S. E. Gathercole (Ed.), Models of shortterm memory (pp. 29-50). Hove, U.K.: Psychology Press.

De Renzi, E., \& Nichelli, P. (1975). Verbal and nonverbal memory impairment following hemispheric damage. Cortex, 11, 341-354.

ELLIOTT, C. D. (1983). British abilities scales. Windsor, U.K.: NFERNelson.

Farah, M. J., Hammond, K. M., Levine, D. L., \& Calvanio, R. (1988). Visual and spatial mental imagery: Dissociable systems of representation. Cognitive Psychology, 20, 439-462.

FARRAND, P., \& JONES, D. (1996). Direction of report in spatial and verbal serial memory. Quarterly Journal of Experimental Psychology, 49A, 140-158.

Flavell, J. H., BeaCh, D. R., \& ChinsKy, J. M. (1966). Spontaneous verbal rehearsal in a memory task as a function of age. Child Development, 37, 283-299.

GatherCoLe, S. E. (1986). The modality effect and articulation. Quarterly Journal of Experimental Psychology, 38A, 461-474.

Gathercole, S. E., \& Adams, A.-M. (1994). Children's phonological working memory: Contributions of long-term knowledge and rehearsal. Journal of Memory \& Language, 33, 672-688.

Gathercole, S. E., Adams, A.-M., \& Hitch, G. J. (1994). Do young children rehearse? An individual-differences analysis. Memory \& Cognition, 22, 201-207.

Gathercole, S. E., \& BAdDeley, A. D. (1993). Working memory and language. Hove, U.K.: Erlbaum.

Gathercole, S. E., \& Hitch, G. J. (1993). The development of rehearsal: A revised working memory perspective. In A. Collins, S. E. Gathercole, M. A. Conway, \& P. E. Morris (Eds.), Theories of memory (pp. 189-210). Hove, U.K.: Erlbaum.

Hanley, J. R., Young, A. W., \& Pearson, N. A. (1991). Impairment of the visuo-spatial sketchpad. Quarterly Journal of Experimental Psychology, 43A, 101-126.

HEALY, A. F. (1974). Separating item from order information in short-term memory. Journal of Verbal Learning \& Verbal Behavior, 13, 644-655.

HEALY, A. F. (1982). Short-term memory for order information. In G. H. Bower (Ed.), The psychology of learning and motivation: Advances in research and theory (Vol. 8, pp. 191-238). New York: Academic Press.

HENRY, L. A. (1994). The relationship between speech rate and memory span in children. International Journal of Behavioral Development, 17, 37-56.

Henson, R. N. A., Norris, D. G., Page, M. P. A., \& Baddeley, A. D. (1996). Unchained memory: Error patterns rule out chaining models of immediate serial recall. Quarterly Journal of Experimental Psychology, 49A, 80-117.

HOCKEY, G. R. J. (1973). Rate of presentation in running memory and direct manipulation of input processing strategies. Quarterly Journal of Experimental Psychology, 25, 104-111.

Hulme, C., Thomson, N., Muir, C., \& Lawrence, A. (1984). Speech rate and the development of short-term memory span. Journal of $E x$ perimental Child Psychology, 38, 241-253.

IsAaCs, E. B., \& VARGHA-KHADEM, F. (1989). Differential course of development of spatial and verbal memory span: A normative study. British Journal of Developmental Psychology, 7, 337-380.

JohNSON, R. S., JoHNSON, C., \& GRAY, C. (1987). The emergence of the word length effect in young children: The effects of overt and covert rehearsal. British Journal of Developmental Psychology, 5 , 243-248. 
Jones, D. M., Beaman, P., \& Macken, W. (1996). The object-oriented episodic record. In S. E. Gathercole (Ed.), Models of short-term memory (pp. 209-238). Hove, U.K.: Psychology Press.

Jones, D. M., FarRand, P., Stuart, G. P., \& Morris, N. (1995). Functional equivalence of verbal and spatial information in serial shortterm memory. Journal of Experimental Psychology: Learning, Memory, \& Cognition, 21, 1008-1018.

LEWANDOWSKY, S., \& MURDOCK, B. B. (1989). Memory for serial order. Psychological Review, 96, 25-57.

Liberman, I. Y., ManN, V. A., Shankweiler, D., \& Werfelman, M. (1982). Children's memory for recurring linguistic and nonlinguistic material in relation to reading ability. Cortex, 18, 367-375.

LoGIE, R. H. (1995). Visuo-spatial working memory. Hove, U.K.: Erlbaum.

Michas, I. C., \& Henry, L. A. (1994). The link between phonological memory and vocabulary acquisition. British Journal of Developmental Psychology, 12, 147-164.

NatrNe, J. S., \& Walters, V. L. (1983). Silent mouthing produces modality- and suffix-like effects. Journal of Verbal Learning \& Verbal Behavior, 22, 475-483.

Nicolson, R. (1981). The relationship between memory span and processing speed. In M. Friedman, J. P. Das, \& N. O'Connor (Eds.), Intelligence and learning (pp. 179-184). New York: Plenum.

PhILlIPS, W. A., \& Christie, D. F. M. (1977). Interference with visualization. Quarterly Journal of Experimental Psychology, 29, 637-650.
Smith, E. E., Jonides, J., \& Koeppe, R. A. (1996). Dissociating verbal and spatial working memory using PET. Cerebral Cortex, 6, 11-20.

Sмyтh, M. M., \& Scholey, K. A. (1996a). The relationship between articulation time and memory performance in verbal and visuo-spatial tasks. British Journal of Psychology, 87, 179-192.

Sмyтн, M. M., \& Scholey, K. A. (1996b). Serial order in spatial immediate memory. Quarterly Journal of Experimental Psychology, 49A, 159-177.

Vallar, G., \& Baddeley, A. D. (1984). Fractionation of working memory: Neuropsychological evidence for a short-term store. Journal of Verbal Learning \& Verbal Behavior, 23, 151-161.

WANG, P. P., \& Bellugi, U. (1994). Evidence from two genetic syndromes for a dissociation between verbal and visual-spatial shortterm memory. Journal of Clinical \& Experimental Neuropsychology, 16, 317-322.

WECHSLER, D. (1974). Wechsler Intelligence Scale for ChildrenRevised. New York: Psychological Corp.

Wilson, J. T. L., SCOTT, J. H., \& Power, K. G. (1987). Developmental differences in the span of visual memory for patterns. British Journal of Developmental Psychology, 5, 249-255.

(Manuscript received April 15, 1997; revision accepted for publication October 20, 1997.) 